This is a pre-print of an article published in Knowledge Management Research \& Practice. The final authenticated version is available online at:

Ribeiro-Soriano, D.E., Berbegal-Mirabent, J. (2017). Disseminating scientific research: a doubleedged sword? Knowl Manage Res Pract 15, 380-390. https://doi.org/10.1057/s41275-017-0070-x

\title{
Disseminating scientific research: A double-edged sword?
}

\begin{abstract}
Practitioners rarely have the time or propensity to read scientific research, and scholarly researchers seldom write for non-academic audiences. Nevertheless, both groups would probably agree that researchers could solve many problems faced by practitioners and that research is important to guide practice. This article acknowledges scientists' failure to communicate successfully with practitioners, and discusses the main differences between academic and practitioner-oriented journals in management and business related disciplines. Author guidelines of the most prominent journals that appeal to both academics and practitioners are reviewed and discussed. A thorough literature review is also conducted to support the arguments. The article offers suggestions on how to narrow the gap between academics and practitioners and how to find a way of not only delivering science to practitioners, but also making science benefit society. Progress is necessary to move toward a better academic-practitioner dialogue and thereby advance both science and practice.
\end{abstract}

\section{Keywords}

Academic journals, practitioner-oriented journals, scientific research, research output, knowledge dissemination, university-industry gap

\section{Introduction}

In Managers not MBAs: A hard look at the soft practice of managing and management development, the distinguished professor of management, Henry Mintzberg (2004), explains the differences between theory and its links with practice. In his book, which specifically addresses MBAs, Mintzberg argues that simply defining an ambitious program is insufficient. For an MBA to be useful and for its students to acquire the knowledge and competencies required by tomorrow's businesses, the course content should cover both what instructors 
think managers need to know and what managers want to learn. Likewise, founders, CEOs, managing directors, executive directors, managers, and consultants-all of whom are practitioners - read only a few academic publications; specifically, those that provide them with information of interest.

Debate centres on the question of how best to disseminate scientific research output to different stakeholders. Knowledge generated at universities and research centers can be disseminated in a variety of forms; nevertheless, academic journals play a dominant role in this process driven by the current system of academic accreditation and recognition. Although researchers view publishing in an academic journal as a noteworthy achievement, if the publication never leaves the same academic circle, the social impact of this research will be minimal — practically non-existent — and hence the resources invested in that research will not yield their expected social returns. We argue that academic journals are necessary to encourage discussion between scholars and thus advance scientific knowledge. They serve as forums for the introduction and presentation for the critique of existing research and the share and scrutiny of new advancements with the academic community. It is also necessary, however, to transfer this knowledge to those who apply it on a daily basis (i.e., practitioners) to improve the performance of their businesses. Researchers have a social responsibility to seek ways of encouraging professionals to use their findings (Rynes, Bartunek \& Daft, 2001). This goal, however, is extremely hard to achieve because the market is saturated with management ideas.

The interests of the two profiles are markedly different. Compared to academics, practitioners are often not aware of the existing scientific literature available in academic journals on key issues in their fields (Sanders, Riemsdijk \& Groen, 2008). On the contrary, they usually place too much trust in best practices published in practical journals rooted in their professional sphere, self-improvement books, personal judgments, own experiences, or 
the beliefs of corporate leaders. The burden of business as usual restricts the time they may spend on reading (Briner, Denyer \& Rousseau, 2009), and they therefore prefer to focus on reading material they believe will prove relevant and will provide value for their businesses (Gopinath \& Hoffman, 1995). Debate has always existed between those who prefer theoretical, non-applied research and those for whom only findings from practical research are of interest (Rawson, Marinelli-Casey \& Ling, 2002).

The aforementioned considerations highlight a gap between practitioners' needs and scientific research dissemination (Bawden, 2015). Academics and practitioners must identify common interests so that they may cooperate to draw upon the scientific knowledge stock. Without losing an academic focus, in this paper we posit that practitioner-oriented journals aim at bridging this gap and primary seek articles that attempt to influence the behavior of managers and executives (Finch, O'Reilly, Foster, Dubak \& Shaw, 2015). Understandably, this type of journals is more likely to achieve greater impact in the professional sphere (Abbot, 2014). This topic is not new, however there is a lack of a systematic review of the main differences between academic and practitioner-oriented journal.

Focusing on management and business related disciplines this article provides a fresh approach to this matter suggesting new insights on how research should be disseminated in order to capture both the attention of academics and practitioners. To explore this debate, we first discuss the gap between research achievements and their practical applications, and conclude that this gap is accentuated because of the way science is currently disseminated, mainly through academic journals which are usually ignored by practitioners. Next, we explore the differences between practitioner-oriented journals and academic journals in terms of their structure and writing style. The procedure followed for this comparison is described in the method section. Finally, the article concludes with some prospective suggestions on 
how to narrow the gap between research and practice to better ensure the dissemination of research results to different audiences.

\section{The gap between research and practice}

Practitioners, generally executives within organizations, are usually familiar with the academic literature owing to their high level of education and training. Nevertheless, evidence suggests that despite being aware of the theoretical foundations upon which their judgements are made, they rarely consult with academics regarding strategy or good practices to improve business operations or boost profits (Rynes, Colbert \& Brown, 2002). Likewise, researchers seldom seek inspiration from professionals when developing research questions or hypotheses' or when interpreting findings. Academics and professionals thus operate within different frameworks with respect to issues such as the type of information used to establish valid foundations for action, the structure of information, and the experiences used to evaluate the validity of assertions regarding current knowledge. Table 1 shows how academics and practitioners formulate and approach problems, evidencing significant differences.

Insert Table 1 about here

Several are the voices that claim that practitioners should give more attention to studies conducted by researchers to become aware of opportunities they could not identify themselves (MacIntosh, Beech, Antonacopoulou \& Sims, 2012). This statement not only applies to business and management fields but can be extended to other disciplines (van Rooi \& Snyman, 2006). In this line of thought, van de Ven (2007) argues that industry managers should seek advice from academics more often that they currently do because the exchange of 
ideas, experiences, and opinions creates synergies while making the evaluation of research findings easier and more flexible. Meanwhile, changes in economic and political status in different countries and contexts have altered the way academics and professionals collaborate. This shift may help close the gap between theoretical and practitioner-oriented research.

Collaboration between researchers and professionals is occurring with increasing intensity, albeit too slowly. Generally, close collaborations between researchers and practitioners may be possible through short-term projects or may endure over a longer period owing to differing economic interests behind different projects. In their quest for rigor, academics dedicate most of their efforts to conducting detailed analysis of a phenomenon's characteristics and illustrating the relationships between concepts, thereby overlooking the broader context and failing to provide an overall understanding of the phenomenon at hand.

The lifeblood of academic research is its rigor regarding concepts and relationships. Whereas academic researchers debate the need to precisely define research problems and investigate them carefully and thoroughly, the reality of the practitioner-oriented researcher's problems calls for a clear, broad perspective of the issue (Bansal, Bertels, Ewart, MacConnachie \& O'Brien, 2012). The strength of practitioner-oriented research lies in its pragmatic approach to studying a problem and its sophistication in articulating that problem. The gap creates a buffer, allowing professionals to grapple with problems and resolve them without interference from researchers, especially when the scientific evidence is vague or ambiguous.

In short, the belief that there does not exist a considerable gap between research and practice is misguided. The gap covers a wide range of skills and knowledge (van de Ven \& Johnson, 2006), and scholars and practitioners continue to discuss the causes of the gap and possible solutions to fill it. With the number of potential solutions to bridge the gap between research and practice, the key question is why such a gap remains. Smith and Lewis (2011) 
suggest that the gap owes to the inherently paradoxical nature of practical and theoretical research. Researchers should not seek to dismantle or neutralize these paradoxes but should instead consider them inherent to research and treat them as existing in a state of dynamic equilibrium.

\section{Method}

Numerous prestigious academic publications appeal to a readership consisting of both academics and practitioners. For the purpose of this paper we have reviewed a selected number of journals that are acknowledged to fall in this category of journals. Particularly, we considered those listed by Gopinath and Hoffman (1995): Harvard Business Review (HBR), MIT Sloan Management Review (MIT SMR), Business Horizons (BH), Strategic Management Journal (SMJ), Organizational Dynamics (OD), California Management Review (CMR), Long Range Planning (LRP), Academy of Management Executive (currently running under the name Academy of Management Perspectives, AMP). This list comprises some of the most relevant journals according to their ranking in top international databases such as Thomson Reuters-Institute for Scientific Information (ISI).

Table 2 summarizes how the aforementioned journals are ranked in the Social Science Citation Index. From this table it can be interfered that despite having a practitioner-oriented focus, these journals enjoy from a strong and reputable impact among the scientific community.

Insert Table 2 about here 
In order to analyse the stylistic features of these journals, we scrutinised in detail both the aims and scope and the authors' guidelines of these journals. Specifically we were interested in capturing how editors ask prospective authors to write their papers. Accordingly, we concentrate on identifying: 1) how the target audience was defined; 2) the suggested research focus; 3 ) the stylistic and language requirements; and 4) any advice on how to write the managerial/policy implications of the results.

We also reviewed the papers that have been published in the journals listed in Table 2 during the last year (2015). Each article was read through with special attention paid to the research method used, data selection and collection, and description of the results. The next section deals with the main common features observed from this analysis. In order to enrich the discussion, we compare the characteristics of practitioner-oriented journals with those of traditional academic journals.

\section{Results: Stylistic differences between academic and practitioner-oriented journals}

\section{Target audience}

Unlike purely academic journals, practitioner-oriented journals target a specific professional market. They differ from other journals in that they target a niche market rather than a broad readership. Practitioner-oriented journals discuss issues not only among academic researchers, but also among business executives and other influential thought leaders. According to the website of the MIT Sloan Management Review, about $77 \%$ of its readers are business executives, $46 \%$ are top managers (founders, owners, CEOs, presidents, or chairpersons), $10 \%$ are management consultants, and $10 \%$ are academics (the total amount equals more than $100 \%$ because some groups overlap). 
Because managers evaluate research in terms of the degree to which they identify with it, practitioner journals should publish research that offers practical implications and expounds good practices that managers can implement in their organization and business environment (Gautam, 2008). For instance, according to its journal description, Business Horizons "fill[s] a unique niche [...] by publishing articles that strike a balance between the practical and the academic."

In addition to boasting a readership consisting of practitioners, practitioner journals encourage contributions from authors with a variety of backgrounds besides academia. In this respect, California Management Review welcomes “articles by practitioners on contemporary business policies and practices." Similarly, Long Range Planning encourages articles written by "practicing managers and students in professional programs."

\section{Focus}

First, practitioner-oriented articles differ from scholarly ones in their research focus. Practitioner-oriented articles aim to "link leading-edge thought and research with management practice" (Organizational Dynamics). They aim to prescribe how managers should act in the real world to improve organizational performance and output. To quote Harvard Business Review's Guidelines for Contributors, “readers come to us not just to stay on top of new developments in management thinking, but also to get help changing the way they and their organizations actually do things." Accordingly, a manager expects articles in the form of recipes for success. Business Horizons stresses this point: The focus should be on "identifying important business issues or problems and recommending solutions that address these."

Second, unlike in scholarly articles, in practitioner-oriented articles it is of little relevance to discuss at length the theoretical background and to establish and validate 
relationships between constructs. Instead, practitioner-oriented articles stress how these relationships work in practice and can improve organizational performance (Kelemen \& Balsan, 2002). The MIT Sloan Management Review's aims and scope state that the editors "aim to find the most potent, useful and directly applicable management insights developed by researchers, academic scholars and influential thought leaders, and translate these new ideas for business executives and management teams who can put them to work." In other words, practitioner-oriented research draws attention to the research findings and applicability rather than to the research process. While theoretical contributions are important, focus should be on scrutinizing and helping to improve managerial practices by offering practitioners specific recommendations and action plans.

This point triggers discussion regarding the relevance of theoretical articles versus practical articles. The main difference is the way researchers formulate and approach problems. Theoretical research is more technical, whereas practical research uses a simpler lexicon. In some knowledge areas, however, the difference between theoretical and practitioner-oriented research is small. According to Brownson, Kreuter, Arrington and True (2006) there are similarities in the research processes behind theoretical and practitioneroriented research. This process has four stages: (1) knowledge discovery or creation, (2) transformation of knowledge into a tangible form of learning, (3) knowledge transfer, and (4) the actual change resulting from the research.

\section{Data collection and method}

Practitioner-oriented and scholarly journals also differ in terms of data collection and analysis methods. Data availability is essential to write an article. Without empirical evidence to test or validate hypotheses or models, an article may lose its appeal, particularly in practitioneroriented journals. Data collection and analysis are fundamental. But whereas academic researchers document this process by certifying that data are comprehensive and systematic 
and that the statistical analysis is sound and rigorous, practitioner-oriented journals contain little discussion regarding data, which the authors have usually gathered in a fairly ad hoc manner and have sought specifically to support individual success stories (Kelemen \& Balsan, 2002). Indeed, in practitioner-oriented journals, statistical evidence is merely illustrative, and such journals typically offer little discussion of the process that yields the numbers. As previously mentioned, practitioner-oriented journals' target readership demands articles that avoid technicalities and complex methods and that clearly and simply present findings and applications. Because of the nature of the data and the research focus, inductive researchopen-ended and exploratory-seems to appeal more to practitioners than deductive research-more narrow and concerned with testing or confirming hypotheses-does. According to Kelemen and Bansal (2002) the rationale behind this lies in the fact that inductive research is easier to translate into language that appeals to managers.

The academic business and management literature displays a broad spectrum of research techniques and methods. Although quantitative methods still dominate qualitative methods, a growing number of prestigious journals are beginning to include mixed methods, whereby quantitative methods supplement qualitative methods and vice versa. This is in fact the very strategy demanded by practitioners. Thus, research is steadily shifting away from complex quantitative models based on statistical methods that are unfamiliar to practitioners, who are more in contact with the day-to-day concerns of business and management. Moreover, traditional approaches such as multiple regression analysis are effective at identifying symmetric relationships; however, there are not always symmetric relationships among the observations (Greckhamer, Misangyi, Elms \& Lacey, 2008).

Comparative research methods such as Qualitative Comparative Analysis (QCA) fill this gap in traditional quantitative analysis offering a novel approach, especially in situations with multilevel explanations and influences (Woodside, 2013). In addition, although this 
method performs well with large data sets, QCA lets researchers analyse small samples and then generalize findings to populations. Studies using this methodology are now appearing in indexed journals ranked highly in the Thomson Reuters-Institute of Scientific Information (ISI). Examples include prestigious journals such as the Academy of Management Journal, the Journal of International Business Studies, Organization Science, Organizational Research Methods, and the Journal of Business Research.

\section{Language}

Besides the aforementioned differences, the main difference between practitioner and academic journals lies in the simplicity and accessibility of the language they use. Purely scientific researchers-generally considered overly theoretical-opt for accuracy. Professionals, in contrast, favour applicability and simplicity above all else. These differences in preferences owe largely to scientific research's strict formal rules, which govern style, format, and vocabulary. This strictness results in high-quality articles that are extremely academically stringent yet that fail to resonate with managers, who perceive such articles as too dry or full of jargon. Accordingly, California Management Review calls for articles that are "as jargon-free as possible."

Practitioners are usually limited by the day-to-day running of their businesses, which generally occupies much of their time. Consequently, they have little time to read and seek solutions in specialist journals. Thus, authors of practitioner-oriented articles must carefully choose less specialist—but nonetheless precise—-language that managers find more accessible and understandable. Therefore, authors of practitioner-oriented articles should communicate clearly, concisely, and directly. Practitioners consistently allude to problems in comprehension when reading academic, theoretical, or non-applied journals because of excessively scientific language (Kieser \& Leiner, 2009). Practitioners lack training in reading these journals, and they seem uninterested in scholarly research as presented by academics 
(Cohen, 2007). To overcome this problem, the author guidelines for Business Horizons clearly state a preference for articles "presented in a readable, non-technical format such that the content is accessible to a wide business audience."

To meet these demands, practitioner-oriented journals draw on numerous rhetorical devices to aid communication with practitioners (Bansal et al., 2012). Articles tend to follow the format of consulting documents: They are shorter and include visual maps and bullet points summarizing main ideas. Indeed, the Harvard Business Review expresses an interest in visual contributions if an "idea would be more useful as an interactive graphic, assessment, checklist, or tool." Such stylistic devices allow practitioners to grasp messages quickly.

In conclusion, the review of articles published in the journals mentioned at the start of this section shows that practitioner-oriented journals contain articles that are simple, address topics that are easy to communicate and grasp, and respond to specific situations (Van de Ven \& Johnson, 2006).

\section{Managerial implications}

When discussing implications, authors tend to first explain what results show about theoretical constructs and principles and the relationships among them. Next, authors question when and in what contexts the observed patterns emerge. Despite these first-order theoretical implications, however, insights gleaned from probing deeper into observed results are of greater interest and value (Geletkanycz \& Tepper, 2012). Authors can thus explore more thoroughly the "real world" implications of their studies.

Both a typical scholarly article and a practitioner-oriented one contain a section devoted to discussing how the research contributes to the literature. Although authors often stress the research's theoretical and scientific contributions, discussing its practical utility is increasingly gaining importance as an acceptance criterion for publication (Corley \& Gioia, 
2011). Academic and business communities have a mutual interest in intensifying the twoway flow of ideas and information, so authors are encouraged to report managerial implications and relevance of their research. Publications should act as a bridge between the academic and business communities. For a journal to accept a paper, an exhaustive literature review and a highly complex model relying on accurate, rigorously processed data are insufficient. Journals increasingly call for authors to identify implications not only for theory and research, but also for practitioners and society.

Many journals' guidelines now state that authors should explain how their research fills the gap between theory and practice, how practitioners can use the research, and how the research can influence public policy. Hence, the research should elaborate not only on its practical implications, but also on its social impact: How will the research affect businesses? What is the research's social impact? How could the research inform public or industry policy? How might it affect quality of life? In short, authors must clarify how their research will affect society.

Practitioner-oriented journals therefore ask authors to present results using a straightforward writing style, clearly indicating how businesses can apply findings to benefit from the research. For instance, Harvard Business Review claims that if the author can explain his or her "thinking so that the reader understands how to begin to apply it in a real situation, that contribution will make it a lot more powerful." Similarly, California Management Review emphasizes the importance of being practitioner oriented. The editorial team of this journal stresses the need to present results by including "prescriptive advice for managers that will help them in their role as manager." Likewise, Organizational Dynamics makes similar requests of authors, demanding that articles show "how research findings can help managers deal more effectively with the dynamics of organizational life." 
Providing an appropriate response to these demands is difficult. Indeed, it represents a key challenge for researchers, who have traditionally been more concerned with providing accurate methodological details than with discussing the managerial implications of their research.

For illustrative purposes, Table 3 summarises the main stylistic differences that have been found between academic and practitioner-oriented journals and that have been described above.

Insert Table 3 about here

\section{Discussion: Next steps}

This article brings new insights into the debate on the stylistic differences regarding how academic and practitioner-oriented journals are disseminating research results to society. By conducting a systematic review of the guidelines of some of the most influential practitioneroriented journals in the business and management fields, we have been able to characterise their focus and scope and compare them with traditional scholarly journals.

Several implications can be drawn from the analysis, pointing to new avenues for researchers and policy-makers. First, there is an urgent need for simultaneously delivering practitioner relevance and scholarly excellence. From the systematic review of the guidelines of some of the most influential practitioner-oriented journals in the business and management fields, we have been able to characterize their focus and scope and compare them with traditional scholarly journals. Because few practitioners have been trained in the skills required to understand pure academic publications, we posit that in order to prevent research 
fails to reach practitioners, scholarly journals should adopt some specific practices to become more attractive to practitioners. These practices include:

- Goal relevance: Research topics should deal with issues that help practitioners have a better hold on factors that are critical to organizational survival and competitiveness - i.e., productivity, sales volume, costs, quality-. This relevance can be checked at the problem formulation stage.

- Operational validity: Variables used to explain organizational performance should be accessible and maneuverable by practitioners; otherwise, it is difficult to figure out how to implement improvements and measure their success.

- Non-obvious findings: Academic research should provide new insight in the form of knowledge and information, going beyond intuition. If results are sound and nonobvious, practitioners would be more willing to read academic research.

- Readability: Research problems should be articulated by employing a more plain vocabulary. Likewise, cutting-edge scientific findings should be communicated in a more meaningful way. The researcher should demonstrate how the findings are useful for someone "doing the job" rather than what s/he knows about the topic.

Second, the absence of institutional incentives and the lack of knowledge within research are two of the main barriers limiting the dissemination of research results to nonacademic audiences (Kelemen \& Balsan, 2002). A possible solution would be to develop a way of citing practitioner-oriented journals in business and management. The commissions in charge of academic assessment could recognize such databases, particularly in terms of the researchers' commitment to the transfer of research findings. Another limitation associated with practitioner-oriented articles is the sponsorship of this type of research. Depending on the stage of the economic cycle, greater or smaller amounts are available for producing 
practitioner-oriented research because such research depends on funding available to firms and professionals' interest in performing such research. A further limitation is professionals' lack of trust. Professionals are cautious in their interactions with researchers owing to the confidentiality of the firm's private data. Competition between firms represents a key limitation for researchers. For fear that other firms might imitate their strategies, firms prefer not to disclose or publish studies containing confidential data.

Third, nothing is so practical as a good theory. Business- and management-related academic journals should avoid adopting a purely theoretical or laboratory focus in favour of practical application. Recalling Mintzberg's (2004) analogy with MBAs, an interesting proposal would be for certain publications to heed managers' proposals regarding what they needed or wanted to learn. Authors - researchers interested in publishing and thus obtaining recognition for their academic careers or for accessing positions in important firms-could channel their efforts and invest time and attention in researching these issues. The editor of the journal, who would request these "tailor made" studies, would bring together the demand of the practitioner and the offer from the researcher seeking to publish his or her research. In addition, some type of financial transaction could help the editorial team to perform its administrative tasks, acting as an intermediary between supply and demand. This approach assumes that practitioners' knowledge complements that of academics'. Consequently, practitioners and academics are called to leverage their unique perspectives to have a holistic understanding about a given phenomenon. This new form of generating research and publishing results is merely a new way of responding to the need for science to benefit society. Furthermore, it would open a new business opportunity for publishers of scientific journals. In a market where growth is increasingly limited owing to fierce competition and open source publication (Peroni, Dutton, Gray \& Shotton, 2015), this alternative could offer a way of reaching a neglected but highly promising market segment, namely practitioners. 
Lastly, practitioners need exposure to scientific evidence to gain knowledge and implement scientific discoveries. Similarly, academics need to work closely with industry because practitioners are closer to users and downstream research and are thus more aware of real problems faced by businesses. In other words, practice needs theories to shape it, and theory is tested and developed through practice. Scholars can no longer lament the absence of knowledge transfer while failing to tackle the whole problem. A need to collectively address this situation exists, but to do so, both academics and practitioners first need to broaden their minds and break away from traditional paradigms. Many classical studies of organizations resulted from the consolidation of solid bonds between academics and practitioners; nevertheless, there are few common arenas where academics and practitioners debate or share knowledge. In the recent years several far-reaching unconventional solutions have been created, responding to this demand. Online platforms such as www.cebma.org,

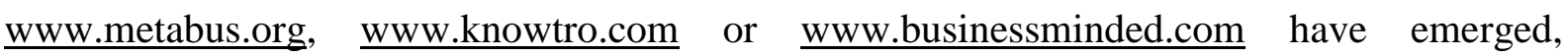
transforming complex language, tables, and statistics from academic papers to more visual and easily accessible information. Known as evidence-based management (EBM), this approach aims at bringing together researchers, practitioners and educators to identify strategic practice questions, ascertain what scientific research tells about each interrogation, and finally deliver this information in a way that supports its use. Inspired by EBM practices, universities, academic journals and other alike research-intensive organizations have increasingly started considering alternative ways for regularly reporting the latest scientific insights in a language accessible to the general audience.

\section{Concluding remarks}

The university's role in the current knowledge-based economy determines whether publications are an end in themselves or merely a means to such an end. Science-based 
institutions such as universities are some of the most important engines for regional development. They play a key role in human capital development and in knowledge creation, which, it is hoped, will positively affect neighbouring regions' innovation systems. Today, basic research outcomes are supposed to lead to applied research with economic and social effects besides production (research) and dissemination (teaching and publication).

Academic and practitioner-oriented journals aim at disseminating the knowledge stock generated at universities and research centres. While the formers do so in a more reduced audience, practitioner-oriented journals cover a broader readership including academics and practitioners. In order to better understand the differences of both types of publications, in this study we have critically analysed and compared their weaknesses and strengths. The ultimate goal is not to define the "ideal" journal but rather to trigger discussions among academics and practitioner on how science is currently disseminated and what steps still need to be performed in order to effectively make use of all its potential.

This study is not free of limitations. Probably, the main limitation relates to the specific analysis of journals in the fields of business and management. Although some of the results and managerial implications can be extrapolated to other disciplines, important differences exit, impeding the generalisation of the results. Another limitation relates to the number of journals reviewed. Although we have followed a systematic procedure for reviewing the guidelines of these journals and results are supported by convincing evidence, future studies should consider incorporating other relevant journals that have been omitted.

\section{References}

Abbott A (2014) The system of professions: An essay on the division of expert labor. The University of Chicago Press, Chicago. 
Bansal P, Bertels S, Ewart T, MacConnachie P and O'Brien J (2012) Bridging the researchpractice gap. Academy of Management Perspectives 26(1): 73-92.

Bawden D (2015) Research and practice revisited. Journal of Documentation 71(3).

Briner RB, Denyer D and Rousseau DM (2009) Evidence-based management: Concept cleanup time? Academy of Management Perspectives 23(4): 19-32.

Brownson RC, Kreuter MW, Arrington BA and True WR (2006) Translating scientific discoveries into public health action: How can schools of public health move us forward? Public Health Reports 121(1): 97-103.

Cohen DJ (2007) The very separate worlds of academic and practitioner publications in human resource management: Reasons for the divide and concrete solutions for bridging the gap. Academy of Management Journal 50(5): 1013-1019.

Corley KG and Gioia DE (2011) Building theory about theory building: What constitutes a theoretical contribution? Academy of Management Review 36(1): 12-32.

Finch DJ, O'Reilly N, Foster WM, Dubak A and Shaw J (2015) Predictors of knowledge transfer: A biographical analysis of authors in leading management journals. Academy of Management Proceedings 2015(1): 12901.

Gautam K (2008) Addressing the Research-Practice Gap in Healthcare Management. Journal of Public Health Management Practice 14(2): 155-159.

Geletkanycz M and Tepper BJ (2012) Publishing in AMJ-part 6: Discussing the implications. Academy of Management Journal 55(2): 256-260.

Gopinath C and Hoffman RC (1995) The relevance of strategy research: Practitioner and academic viewpoints. Journal of Management Studies 32(5): 575-594.

Greckhamer T, Misangyi V, Elms H and Lacey R (2008) Using qualitative comparative analysis in strategic management research: An examination of combinations of industry, corporate, and business-unit effects. Organizational Research Methods 11(4): 695-726. 
Kelemen M and Bansal P (2002) The conventions of management research and their relevance to management practice. British Journal of Management 13(2): 97-108.

Kieser A and Leiner L (2009) Why the rigour-relevance gap in management research is unbridgeable. Journal of Management Studies 46(3): 516-533.

MacIntosh R, Beech N, Antonacopoulou E and Sims D (2012) Practising and knowing management: A dialogic perspective. Management Learning 43(4): 373-383.

Mintzberg H (2004) Managers, not MBAs: A hard look at the soft practice of managing and management development. Berrett-Koehler Publishers, San Francisco.

Peroni S, Dutton A, Gray T and Shotton D (2015) Setting our bibliographic references free: Towards open citation data. Journal of Documentation 71(2): 253-277.

Rawson RA, Marinelli-Casey P and Ling W (2002) Dancing with strangers: Will U.S. substance abuse practice and research organizations build mutually productive relationships? Addictive Behaviors 27(6): 941-949.

Rynes SL, Bartunek J and Daft R (2001) Across the great divide: Knowledge creation and transfer between practitioners and academics. Academy of Management Journal 44(2): $340-355$.

Rynes SL, Colbert AE and Brown KG (2002) HR professionals' beliefs about effective human resource practices: Correspondence between research and practice. Human Resource Management 41(2): 149-174.

Sanders K, van Riemsdijk M and Groen B (2008) The gap between research and practice: A replication study on the HR professionals' beliefs about effective human resource practices. International Journal of Human Resource Management 19(10): 1976-1988.

Smith WK and Lewis MW (2011) Toward a theory of paradox: A dynamic equilibrium model of organizing. Academy of Management Review 36(2): 381-403. 
Van de Ven AH (2007) Engaged scholarship: A guide for organizational and social research. Oxford University Press, London.

Van de Ven AH and Johnson PE (2006) Knowledge for theory and practice. Academy of management review 31(4): 802-821.

Van Rooi H and Snyman R (2006) A content analysis of literature regarding knowledge management opportunities for librarians. Aslib Proceedings 58(3): 261-271.

Woodside AG (2013) Moving beyond multiple regression analysis to algorithms: Calling for adoption of a paradigm shift from symmetric to asymmetric thinking in data analysis and crafting theory. Journal of Business Research 66(4): 463-472. 


\section{List of Tables}

Table 1. Main differences between how academics and practitioners formulate and approach problems.

\begin{tabular}{|l|l|l|}
\hline & \multicolumn{1}{|c|}{ Academics } & \multicolumn{1}{c|}{ Practitioners } \\
\hline Approach & $\begin{array}{l}\text { Begin with a hypothesis. } \\
\text { Follows a top-down approach, } \\
\text { moving from the more general to } \\
\text { the more specific. }\end{array}$ & $\begin{array}{l}\text { Begin with a research question. } \\
\text { Concerned with the generation of } \\
\text { new theory emerging from data. } \\
\text { The aim is usually focused on } \\
\text { exploring new phenomena or } \\
\text { looking at a previously studied one } \\
\text { from a different perspective. }\end{array}$ \\
\hline Information & $\begin{array}{l}\text { Data availability is essential. } \\
\text { Data are comprehensive and } \\
\text { systematic and that the statistical } \\
\text { analysis is sound and rigorous. }\end{array}$ & $\begin{array}{l}\text { Statistical evidence is merely } \\
\text { illustrative. } \\
\text { Evidence comes from personal } \\
\text { experience, best practices, } \\
\text { colleagues, key opinion leaders, etc. }\end{array}$ \\
\hline
\end{tabular}


Table 2. List of selected journals.

\begin{tabular}{|c|c|c|c|c|}
\hline Journal & $\begin{array}{l}\text { 1-year } \\
\text { impact } \\
\text { factor }\end{array}$ & $\begin{array}{l}\text { 5-year } \\
\text { impact } \\
\text { factor }\end{array}$ & Field & Position $^{\mathrm{b}}$ \\
\hline \multirow{2}{*}{$\begin{array}{l}\text { Academy of Management } \\
\text { Perspective }\end{array}$} & \multirow{2}{*}{3.940} & \multirow{2}{*}{5.223} & Business & $9 / 120(\mathrm{Q} 1)$ \\
\hline & & & Management & $16 / 192(\mathrm{Q} 1)$ \\
\hline \multirow{2}{*}{$\begin{array}{l}\text { Strategic Management } \\
\text { Journal }\end{array}$} & \multirow{2}{*}{3.380} & \multirow{2}{*}{5.972} & Business & $15 / 120(\mathrm{Q} 1)$ \\
\hline & & & Management & 21/192 (Q1) \\
\hline \multirow{3}{*}{ Long Range Planning } & \multirow{3}{*}{2.936} & \multirow{3}{*}{6.619} & Business & $22 / 120(\mathrm{Q} 1)$ \\
\hline & & & Management & 28/192 (Q1) \\
\hline & & & $\begin{array}{l}\text { Planning \& } \\
\text { Development }\end{array}$ & 3/55 (Q1) \\
\hline \multirow{2}{*}{ Harvard Business Review } & \multirow{2}{*}{2.249} & \multirow{2}{*}{2.711} & Business & $33 / 120(\mathrm{Q} 2)$ \\
\hline & & & Management & $46 / 192(\mathrm{Q} 1)$ \\
\hline \multirow{2}{*}{$\begin{array}{l}\text { MIT Sloan Management } \\
\text { Review }\end{array}$} & \multirow{2}{*}{2.114} & \multirow{2}{*}{3.104} & Business & $41 / 120(\mathrm{Q} 2)$ \\
\hline & & & Management & $58 / 192(\mathrm{Q} 2)$ \\
\hline Business Horizons & 1.992 & 2.913 & Business & $83 / 120(\mathrm{Q} 3)$ \\
\hline \multirow{2}{*}{$\begin{array}{l}\text { California Management } \\
\text { Review }\end{array}$} & \multirow{2}{*}{1.109} & \multirow{2}{*}{2.590} & Business & 75/120 (Q3) \\
\hline & & & Management & $115 / 192(\mathrm{Q} 3)$ \\
\hline \multirow{3}{*}{ Organizational Dynamics } & \multirow{3}{*}{0.522} & \multirow{3}{*}{1.101} & Business & $105 / 120(\mathrm{Q} 4)$ \\
\hline & & & Management & $166 / 192(\mathrm{Q} 4)$ \\
\hline & & & $\begin{array}{l}\text { Applied } \\
\text { Psychology }\end{array}$ & $67 / 79(\mathrm{Q} 4)$ \\
\hline
\end{tabular}

${ }^{\mathrm{a}}$ Impact factor according to the Thomson Reuters-Institute for Scientific Information. This number represents the average number of times at which an article appearing in a journal is cited in the two years after publication. The figure given here refers to year 2015.

${ }^{\mathrm{b}}$ Quartile indicated in brackets. 
Table 3. Stylistic differences between academic and practitioner-oriented journals.

\begin{tabular}{|c|c|c|c|}
\hline \multicolumn{2}{|c|}{ Characteristics } & Academic journals & $\begin{array}{c}\text { Practitioner-oriented } \\
\text { journals }\end{array}$ \\
\hline \multirow{2}{*}{$\begin{array}{l}\text { Target } \\
\text { audience }\end{array}$} & Readership & Mainly academics & $\begin{array}{l}\text { Specific professional } \\
\text { market and academics }\end{array}$ \\
\hline & Authorship & Mainly academics & $\begin{array}{l}\text { Variety of backgrounds } \\
\text { besides academia }\end{array}$ \\
\hline \multirow[t]{2}{*}{ Focus } & Orientation focus & $\begin{array}{l}\text { Descriptive, in order to } \\
\text { clearly establish and } \\
\text { validate the relationships } \\
\text { between constructs }\end{array}$ & $\begin{array}{l}\text { Prescriptive. Articles in } \\
\text { the form of recipes }\end{array}$ \\
\hline & Research focus & Research process & $\begin{array}{l}\text { Research findings and } \\
\text { applicability }\end{array}$ \\
\hline \multirow{3}{*}{$\begin{array}{l}\text { Data } \\
\text { collection } \\
\text { and method }\end{array}$} & $\begin{array}{l}\text { Data collection } \\
\text { and processing }\end{array}$ & $\begin{array}{l}\text { Comprehensive and } \\
\text { systematic discussion }\end{array}$ & Little discussion \\
\hline & $\begin{array}{l}\text { Statistical } \\
\text { evidence }\end{array}$ & $\begin{array}{l}\text { High, as a signal of } \\
\text { robustness and academic } \\
\text { rigor }\end{array}$ & $\begin{array}{l}\text { Mainly for illustrative } \\
\text { purposes }\end{array}$ \\
\hline & Method & Quantitative, qualitative & Qualitative \\
\hline \multirow{3}{*}{ Language } & Writing style & $\begin{array}{l}\text { Formal rules, } \\
\text { institutionalized }\end{array}$ & Straightforward, visual \\
\hline & Vocabulary & Full of jargon & Concise, clear and direct \\
\hline & Format & Technical reports & Consulting documents \\
\hline $\begin{array}{l}\text { Managerial } \\
\text { implications }\end{array}$ & $\begin{array}{l}\text { Discussion of the } \\
\text { results }\end{array}$ & $\begin{array}{l}\text { Theoretical and scientific } \\
\text { contribution }\end{array}$ & Practical utility \\
\hline
\end{tabular}

Source: Self-reported. 